\title{
Social support as a mediator between social identity and college student's stress
}

\author{
Ummu Umayyah \\ Graduate School of Universitas Negeri Yogyakarta, Jl. Colombo No. 1, Depok, Sleman, Yogyakarta, \\ Indonesia \\ ummuumayyah006@gmail.com
}

\begin{abstract}
This study aims to find social support as a mediator of social identity against student stress. This study uses a stage cluster random sampling technique, the subject of this study amounted to 375 students scattered on 7 faculties at Yogyakarta State University. The result of the research shows that the social identity level of students is high, social support is high and stress level is classified. The path analysis a proved significant with the value of $0.036<0.05$, on path analysis proved significant with a value of 0.016 $<0.05$, in path analysis proved significant with a value of $0.000<0.05$, and path analysis was proved significant with value $0.000<0.05$. Mediation analysis is evident and includes partial mediation.
\end{abstract}

Keywords: social identity, social support, stress, mediator, student

\section{Introduction}

In general, the experience of entering college is an important transitional period in life and an important rule in the development of individual identity (Cassidy, 2004, p.339). According to Sherman (1994) everyone is trying to build a social identity. According to Tajfel (1982) and Turner (1986) argued that one's social identity is determined by the group in which the individual is incorporated. Building a new social identity in college is inseparable from a problem. Building a social identity and social category process plays a key role in building a person's stress experience and therefore stress arises (Haslam, Jetten, O'Brein, \& Jacobs, 2004). According to Sussman (2000) (in Baron \& Byrne, 2003, p. 164), when a person's social context changes, building a new social identity can be a great source of stress. Students, especially new students are partially stressed (D'Zurilla $\&$ Sheedy, 1991) because of the transition environment to campus life (Towbes \& Cohen, 1996). Stress can be very disturbing, even detrimental to students who can not solve the problem. For some students, stress is very dangerous in college life because some level of stress will cause problems that effect the life of the student and maybe every business will fail (Kumar \& Bhukar, 2013). Lazarus and
Folkman (1984) suggest that the complexity of stress occurs due to the relationship between individuals and the environment regardless of the interaction of internal and external factors. Other research (Kohn et al., 1994, Perrez, 1992) found that every day 'troublesome' in everyday life (conflict with spouse, friends, family, struggling with academic standards, betrayed by friends or rejected by social) Negative physical and mental health more in life. Many previous studies link stress with students. High levels of stress have been associated with symptomology, depression, low well-being (Frazier \& Schauben, 1994; McClain \& Abramson, 1995). Nelson (1995) reports that the first and fifth years of college students have high stress experience than students in the middle year. They argue that in the first year students may experience more stressful experiences due to their major life transition from high school to university.

Students in previous studies reported using strategies when they were getting high levels of stress (Oakland \& Ostell, 1996). According to some previous research results that can make the stress level of the students is to receive support by others. Dunkley, Blankstein, Halsall, Williams, and Winkworth, (2000), Elliott, Herrick, and Witty (1992), reported a significant negative relationship between high social support and low levels of 
student stress. Social support that is part of social interaction within and outside the group, receiving information support has an effect on the surrounding social circumstances (Turner, 1991). In some sections, because identity sharing is the basis of mutual giving and receiving social support (Haslam, 2005, p. 357). According to Morgan (in Baron $\&$ Byrne, 2003, 244) part of the reason is that relationships with others are a source of comfort when we feel depressed. Social support is a useful thing when individuals experience stress, and something very effective regardless of which strategy is used to deal with stress (Frazier, 2000). Haslam, Jetten, O'Brein, and Jacobs (2004) found that students who received information support suggested them to decipher math tasks as challenges and friendliness (just from stress or stress), this is only a positive effect of stress level if it is provided in the group more than his out-group.

The social category process is thought to reduce the stress experienced by the individual, the social category process that is part of the social identity process can protect the individual from stress by receiving support from within or outside his group (Branscombe, 1999). Perceptions of receiving support from a person have a significant influence on the way individuals get to gather information about identity (Bosch, Segrin, and Curran, 2012). Previous research has also found that the process of self-identification of individuals in their social lives will try to help other individuals (Levine, 2002). That support helps the individual to overcome the potential stress that will occur (Aspinwal \& Taylor, 1997). In previous studies (Haslam, 2004) used patients and bomb squad teams as respondents. While this Research takes the first year students to know better about the dynamics of social identity experienced by students during the transition period. New students in collecting information about their social identity have a demand to be able to understand themselves in social life, it can bring stress for students. Therefore this research is emphasized on social support as mediator of social identity process during transition from high school to college to stress experienced by first year batch student.

\section{Social Identity}

Social identity is defined as the individual's knowledge that an individual belongs to a particular social group together with some emotional meaning and value of group membership (Tajfel 1972a, p. 31). Baron and Byrne (2003) state that social identity does not come by itself. The establishment of an identity is a process of motivation. According to Hogg (2004, p. 252), the perspective of social identity is self-awareness whose main focus is more specifically given to inter-group relationships, or relationships among individual members of small groups. Tajfel (1982) and Turner (1986) suggest that a person's social identity is determined by the group in which the individual is affiliated. Turner, Hogg, Oakes, Reicher and Wetherell argue that social identity theory explains that the process of social identity formation by individual self-categorization by reflection of something that becomes object and can be categorized, classified so that it becomes part or related to the social category in question. Social groups are two or more individuals who share social identities both public and private, or almost identical, meaning to assume the individual self as a member of the same social category (Turner 1982, p. 15). According to Hogg (2004), social identity is generally viewed as an analysis of intergroup relationships among social categories on a large scale and social identity is also defined as the process of forming cognitive conceptions of social groups and group members. One result of self-categorization is the increasing of social identity and the decline of personal identity, group identity, group objectives, and the influence of other group members becomes more important than personal identity, personal goals, and personal motives in guiding beliefs and behavior (Oakes, Haslam, \& Turner, 1994).

\section{Social Support}

Social support can be interpreted as a perceived pleasure, concern, appreciation, or assistance received by someone from another person or from his group. This social support includes five dimensions, namely emotional 
support, award support, support in the form of direct assistance, information support and support from social networks (Sarafino, 1994, p. 102). The definition of social support refers to the comfort, attention, appreciation, or assistance provided by others or groups to individuals (Sarafino, 2006). Cohen and Wills (1985) define social support as the help and support one gets from interacting with others. Meanwhile, according to Jacob (in Orford, 1992), social support is a form of behavior that fosters a sense of comfort and makes individuals believe that individuals are respected, respected, loved and others willing to give attention and security. According to Sarafino (2002), social support refers to comfort, caring, self-esteem or any form of assistance that individuals receive from others or groups. Social support is defined by Gottlieb as verbal or non-verbal information, means, assistance, real or behavior given by persons familiar with the subject in their social environment or in the form of attendance and matters that may provide an emotional advantage or effect on The behavior of the recipient. According to Sarafino (2002), the support received by someone from others can be called with social support. Social support can include emotional support, awards or selfesteem support, instrumental support, information support or group support. According to the World Health Organization (2003), stress is the reaction or the body's response to mental stress or the burden of life.

\section{Stress}

Stress according to Sarafino (1990) can be classified in various viewpoints such as: Stress as a stimulus or independent variable affecting the individual state, stress is seen as a response or dependent variable, and stress is the result of interaction with the environment. There are two components of stress that is the psychological response shown by behavior, mindset, and emotion as well as physiological responses. According to Taylor (1995), stress is the result of an individual assessment process relating to personal resources it has to face the demands of the environment. Taylor (1995) says that stress response can be physiological, cognitive, emotional, and behavioral responses. Stress events at least there are two interrelated things that are things, events, people, and circumstances that are the sources of stress. And people who experience stress (Harjana, 1994, p. 11).

\section{Method}

The population of 5,780 undergraduate students of Yogyakarta State University class of 2016 consists of seven faculties. According to Leon and Pagoso's Table (in Wagiran, 2014, pp. 172-173), if the population is around 5,000-6,000, the samples taken are about 375 respondents. After that, the researcher used the a stage cluster random sampling technique to determine the respondents of the study. Starting from one university area in the cluster to seven faculties. Based on the number of students, each faculty found the percentage of respondents per faculty as presented in Table 1.

\section{Measure}

Social identity scale adapted from AIQIV from Cheek and Briggs (2013), with 42 items. Measures 4 aspects, namely personal identity orientation, relationship identity orientation, social identity orientation, and collective identity orientation. Each item consists of a value of 1-5 answers. Through the 42 item expert judgment it becomes 48 points, due to some confusing points on two different activities. The grains were validated using product moment correlation, found seven grains of fall $(11,14,22,24,31,34,48)$ because the correlation was less than 0.3 and 41 grains. The social support scale used is the list of interpersonal support evaluations from Cohen (1985). With 12 points to measure 3 dimensions of social support. All the items in the validation through product moment correlation and all have a correlation above 0.3 so there are 12 points. Each dimension is measured by 4 items and has 1-4 points. The stress scale used is the stress scale from Cohen (1983). Consists of 10 items. Consists of $1-5$ points. The 10 grains were validated by product moment correlation and 3 grain drops $(4,7,8)$ leaving the remaining 7 items. Based on the result of reliability test of social 
Table 1. Percentage of respondents

\begin{tabular}{|c|c|c|c|}
\hline No & Purpose & Details & Description \\
\hline 1. & $\begin{array}{l}\text { To know the sample for } \\
\text { faculty of educational science }\end{array}$ & $\begin{array}{l}\frac{8.44}{5.780} \times 100 \%=15.467 \\
\% \frac{15,467}{100} \times 375=58.001\end{array}$ & $\begin{array}{l}\text { Number of samples for faculty of } \\
\text { educational science: } 58 \text { students }\end{array}$ \\
\hline 2. & $\begin{array}{l}\text { To know the sample for } \\
\text { faculty of language and art }\end{array}$ & $\begin{array}{l}\frac{995}{5.780} \times 100 \%=17.215 \% \\
\frac{17.215}{100} \times 375=64.556\end{array}$ & $\begin{array}{l}\text { Number of samples for faculty of } \\
\text { language and art: } 65 \text { students }\end{array}$ \\
\hline 3. & $\begin{array}{l}\text { To find the sample for the } \\
\text { faculty of mathematics and } \\
\text { natural sciences }\end{array}$ & $\begin{array}{l}\frac{777}{5.780} \times 100 \%=13.443 \% \\
\frac{13.443}{100} \times 375=50.441\end{array}$ & $\begin{array}{l}\text { Number of samples for faculty of } \\
\text { mathematics and natural sciences: } \\
50 \text { students }\end{array}$ \\
\hline 4. & $\begin{array}{l}\text { To find the sample for the } \\
\text { faculty of social sciences }\end{array}$ & $\begin{array}{l}\frac{665}{5.780} \times 100 \%=11.505 \% \\
\frac{11.505}{100} \times 375=43.143\end{array}$ & $\begin{array}{l}\text { Number of samples for faculty of } \\
\text { social sciences: } 43 \text { students }\end{array}$ \\
\hline 5. & $\begin{array}{l}\text { To find the sample for the } \\
\text { faculty of engineering }\end{array}$ & $\begin{array}{l}\frac{1194}{5.780} \times 100 \%=20.657 \% \\
\frac{20,657}{100} \times 375=77.463\end{array}$ & $\begin{array}{l}\text { Number of samples for faculty of } \\
\text { engineering: } 78 \text { students }\end{array}$ \\
\hline 6. & $\begin{array}{l}\text { To find the sample for the } \\
\text { faculty of sport science }\end{array}$ & $\begin{array}{l}\frac{513}{5.780} \times 100 \%=8.875 \% \\
\frac{8.875}{100} \times 375=33.281\end{array}$ & $\begin{array}{l}\text { Number of samples for faculty of } \\
\text { sport science: } 33 \text { students }\end{array}$ \\
\hline 7. & $\begin{array}{l}\text { To find the sample for the } \\
\text { faculty of economy }\end{array}$ & $\begin{array}{l}\frac{742}{5.780} \times 100 \%=12.837 \% \\
\frac{12,927}{100} \times 375=48.138\end{array}$ & $\begin{array}{l}\text { Number of samples for faculty of } \\
\text { economy: } 48 \text { students }\end{array}$ \\
\hline
\end{tabular}

Table 2. Formulas for categories on each variable

\begin{tabular}{lllll}
\hline \multirow{2}{*}{ Formula } & \multirow{2}{*}{ Category } & \multicolumn{3}{c}{ Variable } \\
\cline { 3 - 5 } & & \multicolumn{1}{c}{ Social Identity } & \multicolumn{1}{c}{ Social Support } & \multicolumn{1}{c}{ Stress } \\
\hline$(M+1 S D)$ & High & $(123+1.13 .67)=x>136.67$ & $(24+1.3)=x>27$ & $(14+1.1,17)=\mathrm{x}>15.17$ \\
$(M-1 S D)-(M+1 S D)$ & Medium & $109.33 \leq \mathrm{x} \geq 136.67$ & $21 \leq \mathrm{x} \geq 27$ & $12,83 \leq \mathrm{x} \geq 15.17$ \\
$(\mathrm{M}-1 \mathrm{SD})$ & Low & $(123-1.13 .67=\mathrm{x} \leq 109.33$ & $(24-1.3=\mathrm{x} \leq 21$ & $(14-1.1,17=\mathrm{x} \leq 12.83$ \\
\hline
\end{tabular}

identity variable has coefficient value of 0.904 alpha, on social support variable coefficient value of alpa equal to 0.796 , while at variable of stress coefficient value of equal to 0.812 . The more the coefficient of negligence approaches the value of 1 the better.

\section{Categorization}

The mean value of social identity is 82 , the standard deviation of 13.67. The mean value of social support is 30 , the standard deviation is 3, while the mean stress is 14 and the standard deviation is 1.17 . Based on the mean and standard deviation results are classified into 3 levels: high, medium, and low (see Table 2).
The values of social identity categories include higher than 136.67, medium category values between 109.33 and 136.67, and at lower category values less than 109.33. Social support category values include high over 27 , medium category values between grades 21 and 27 , and on lower category values of less than 21. Stress category values include high over 15.17, medium category values are between grades 12.83 and 15.17 , and at a low category value of less than 12.83. After that on each faculty determined according to the standard score categories found the results as seen in Table 3. 
Table 3. Category by faculty

\begin{tabular}{|c|c|c|c|c|c|c|c|c|c|c|}
\hline \multirow{2}{*}{ Faculty } & \multicolumn{3}{|c|}{ Social Identity Category } & \multicolumn{3}{|c|}{ Social Support Cateogry } & \multicolumn{3}{|c|}{ Stress Category } & \multirow{2}{*}{ Total } \\
\hline & High & Medium & Low & High & Medium & Low & High & Medium & Low & \\
\hline $\begin{array}{l}\text { Educational } \\
\text { Sciences }\end{array}$ & 54 & 4 & 0 & 51 & 7 & 0 & 15 & 26 & 17 & 58 \\
\hline Languages and Art & 53 & 5 & 2 & 59 & 6 & 0 & 29 & 22 & 14 & 65 \\
\hline $\begin{array}{l}\text { Mathematics and } \\
\text { Natural Science }\end{array}$ & 42 & 8 & 0 & 48 & 2 & 0 & 15 & 20 & 15 & 50 \\
\hline Social Science & 41 & 2 & 0 & 42 & 1 & 0 & 12 & 21 & 10 & 43 \\
\hline Engineering & 74 & 4 & 0 & 74 & 3 & 1 & 19 & 35 & 25 & 78 \\
\hline Sport Science & 27 & 5 & 1 & 30 & 3 & 0 & 17 & 12 & 4 & 33 \\
\hline Economy & 43 & 5 & 0 & 45 & 3 & 0 & 18 & 17 & 13 & 48 \\
\hline
\end{tabular}
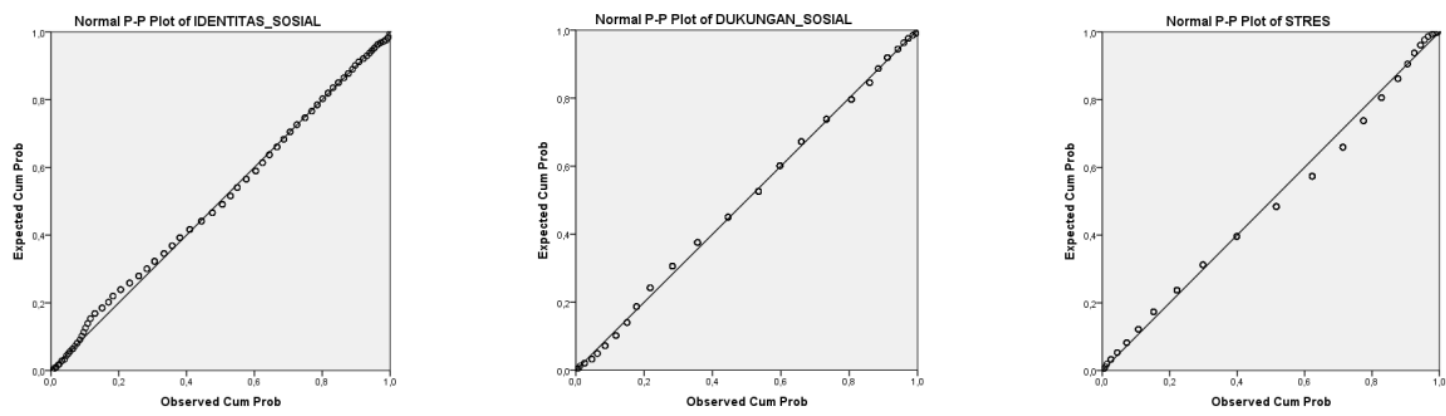

Figure 1. Plots of social identity, social support, and stress

Based on Table 3, the categories of social identity in each faculty are high, the average student has a high value for the process of social identity. Social support categories on each faculty are high, the average student has a high score in obtaining social support. Categories of stress in every faculty including moderate, average students experience stress at a moderate level. This can be corroborated by other research results, Haslam (2004) states that social support can be a contributor to the low levels of stress experienced during the process of social identity.

\section{Findings and Discussion}

Findings

In this study there is a prerequisite test conducted in advance to see the data is good. The prerequisite test of data normality using the One Sample Kormonogorov-Smirnov Test technique has the hypothesis: Data is normally distributed.

Social identity variable has asysmtotic significance value 0.318 more than 0.05 so social identity variable has normal data. Social support variables have asysmtotic significance value of 0.126 over 0.05 so that social support variables have normal data. Stress variable has asysmtotic significance value more than 0.101 so that stress variable have normal data. The data is reinforced by the plots presented in Figure 1.

Based on the P-Plot, the social identity data, social support and stress proved normal. Looking at the diagonal line indicates that the dots are located or near the line with the diagonal.

Test autocorrelation prerequisite using Durbin Watson (DW). The value in this study DW 1.906, with the value of $\mathrm{Du} 1.8762$ on the DW table using $\mathrm{k}=2$ independent variables and the number of respondents $\mathrm{N}=$ 375. It is known that DW value is higher than $\mathrm{Du}$ value and it can be concluded that there is no autocorrelation. The multicollinearity prerequisite test uses the Variance Infinity Factor (VIF) value of 1.009 to less than 10, while the tolerance value of 0.991 is greater than 0.100 so it can be concluded that there is no multi- 
collinearity. Test the dummy variable by using the qualitative variable of sex, to know the effect of gender on stress experienced by the student. Researchers use these provisions: female $=0$, male $=1$. Thus, the hypothesis is as follows: Gender has an influence on stress levels experienced by students.

Based on the results of SPSS, it is found that the significance value $0.286<0.05$. Then, the decision is no gender effect on the level of stress experienced by students.

\section{Regression}

Data analysis in this study using the provisions (Baron \& Kenny, 1986). There are four stages of assumption test, so it can be called that variable mediator. Stage 1 path analysis $\mathrm{c}$ is to connect simple regression analysis between independent variable $\mathrm{X}$ with dependent variable $\mathrm{Y}$, regression analysis $\mathrm{c}$ significance value is $0.36<0.05$. Stage 2 path analysis $\mathrm{a}$ is connecting simple regression analysis between independent variable $\mathrm{X}$ with variable mediator $\mathrm{M}$. Regression analysis a significance value is $0.16<0.05$. Stage $3 \mathrm{~b}$ path analysis is to connect a simple regression analysis between the $\mathrm{M}$ mediator variable and the dependent variable $\mathrm{Y}$. The regression analysis $b$ significance value is $0.00<0.05$. Stage 4 path analysis $c$ 'is connecting multiple regression analysis between independent variable $\mathrm{Y}$ and variable mediator $\mathrm{M}$ with dependent variable $Y$. Regression analysis $c^{\prime}$ significance value $0.00<0.05$. Thus, the hypothesis is as follows: Social support becomes the mediator of social identity and student stress.

Table 4. Regression test results

\begin{tabular}{ll}
\hline \multicolumn{1}{c}{ Variable } & Significance \\
\hline$c=\mathrm{X}-\mathrm{Y}$ & $0.036<0.05$ \\
$a=\mathrm{X}-\mathrm{M}$ & $0.016<0.05$ \\
$b=\mathrm{M}-\mathrm{Y}$ & $0.000<0.05$ \\
$c=\mathrm{X}-\mathrm{M}-\mathrm{Y}$ & $0.000<0.05$ \\
\hline Note. $p<0.05$ &
\end{tabular}

Table 4 shows that the hypothesis of this study is fulfilled, that social support is the mediator of social identity and stress experienced by students. Meanwhile, according to Baron and Kenny (1986) about the mediator intended in this study including partial mediation, because the path c 'variable X-Y remains significant and its value decreases after the included variable $\mathrm{M}$, so called partial mediator. The previous research results also strengthen the results of this study. Haslam (2005) mediated the effect seen, meaning that there is a significant relationship between mediator and social identity. When stress in regression with (social identification) social identity and social support proved to be significant.

Table 5. R squared and beta values

\begin{tabular}{lcc}
\hline \multicolumn{1}{c}{ Variable } & R Squared & Beta \\
\hline$c=$ X-Y path & 0.012 & 0.108 \\
$a=$ X-M path & 0.009 & 0.097 \\
$b=$ M-Y path & 0.117 & -0.343 \\
$c=$ X-M-Y path & 0.138 & 0.143 \\
& & -0.356 \\
\hline
\end{tabular}

The $\mathrm{R}$ squared of the path analysis is 0.012, while the results of the path analysis of $c^{\prime}$ when the variables of social support mediator are included between the social identity variables and the random stress indicate an increase of 0.138 indicating that there is an influence of social support mediation on social identity variables on stress. While on the Beta path analysis c shows the value of 0.108 , at the time of analysis path $c^{\prime}$ indicates that the value of Beta has increased that is equal to 0.143 . The Beta value of path $b$ analysis increments initially a sum of -0.343 to -0.356 when entering the path analysis $c^{\prime}$. It shows that the influence of social mediator variables support social identity and stress on students.

\section{Discussion}

Based on the analysis done by the researcher, the social identity level of Yogyakarta State University students is high, considering there are 7 faculties that have high value in social identity process. On social identity concerning the process of social identification, social category, and social comparison. The student's social interaction will depend on his previous ability to understand social identity. The possibility of a social identity develops in line with the knowledge of the individual self when joining his group (Cinnirella, 1998). At the beginning of the student entering a university, he will begin to identify himself with the new environment around him, at a later 
stage the individual will categorize himself/ herself with his/her social group or life, thus doing a comparison with his social environment so that the student can understand his new environment well. Therefore, the social identity of students is high. As well as social support found by students from their social environments while in college are ranked at a high level, while social support is often found by students tend to be related to everyday life, such as material and non-material assistance. The results of the previous studies also suggest that students receive high social support from friends because students are supported by an educational environment in small classes that provide students with opportunities to help each other and feel professionalism in their academic groups (Dwyer, 2001).

The stress experienced by UNY undergraduate students is moderate, based on the results of categorization of four of seven faculties are in the category of being. The level of stress in each individual can be different, depending on the individual itself. It is confirmed by Marks (2015) that individuals have a certain level of tolerance for stress. One of the factors that can make the stress experienced by UNY students is low is the effect of receiving social support on the process of social identity, in accordance with previous results showed that UNY students have a high level in receiving social support. Social support can reduce the effects of stress experienced by individuals so that students' stress levels are not high or moderate. Haslam, Jetten, O'Brien, and Jacobs (2004) found that students who received information support became a positive effect on stress, stress levels would decrease. Receiving social support will consistently protect individuals from the effects of stress (Cohen, 1992).

Based on the results of the study, researchers found that gender does not have an influence in the stress process experienced by students. Based on the results of hypothesis, testing research in this study found that independent variables $(\mathrm{X})$ social identity significant to the dependent variable $(\mathrm{Y})$ stress. In line with the intervening variable analysis that there must be influence between independent variables and dependent variables as the form of line a. According to Haslam (2005) social identity and social category process is a key role in the development of one's stress experience. While the positive relationship occurs between the student identity against student stress, the positive relationship is meant if the social identity experienced by students is high, then the stress experienced by students is high. In addition, as for other conditions in the intervening variable analysis is path $\mathrm{b}$ that must be significant or have influence. In line $\mathrm{b}$ consisting of independent variables $(\mathrm{X})$ the social identity of the mediator $(\mathrm{M})$ variable or social support is also found to be significant. Positive relationship on line $\mathrm{b}$ is known that if the higher the social identity of the student then the higher the social support will be found by the students, and vice versa the lower level of student's social identity the lower the level of support obtained. This is inseparable from the process of social identity that requires a lot of influence from support around individuals. The distinction between social identity and social support is underlined into a relationship that social identity makes individuals receive social support. Social support contributes to the development of social identity (Stephen, 2015). In certain parts, shared identity gives the opinion that individuals give and receive social support (Haslam, 2005). The results of previous research confirmed that the existence of social identity relation to social support of students, so the higher social identity of students the higher the social support found by the students. Amplified by Haslam (2005) the circular relationship between social identity and social support, which social support also influences the development of social identification in the process of social identity. Sharing identity is one form of group support or the surrounding environment. Various previous research results corroborate the results of this study.

Proves the significance of the path $\mathrm{c}$, ie the influence of the variable $(\mathrm{M})$ on the variable $(\mathrm{Y})$ which also proved significant. The relationship shown by the negative path $\mathrm{c}$ path analysis means that if the social support received by the student is high then the student stress level will be low, and if the social support received by the student is low then the 
stress level experienced by the student is high. The results were also reinforced by Haslam (2004), Branscombe (1999), and also Postmes and Branscombe (2002) who state that support (in the group) will reduce the effects of stress. Social support relationships will have a stress-reduction effect (House, 1981).

The last path analysis is path analysis c ', indirect influence of social support as mediator variable to identity as an independent variable and stress as a dependent variable so that hypothesis of this research is significant. In the previous research results also strengthen the results of this study. Haslam (2005) insists that mediation effect is seen, meaning that there is a significant relationship between mediator and social identity. When stress in regression with (social identification) social identity and social support proved to be significant. Social support becomes a mediator between social identity and stress variables. The results of this study are corroborated by other research results, which prove indirect influence of social support as a mediator. Social support has an indirect effect on individual identity (Cassidy, 2004). The assumptions of path analysis are met, path a significant analysis, significant b path analysis, significant path c analysis, and path analysis are also significant. The hypothesis of this study is fulfilled, that social support memediatori social identity and stress experienced by students. Meanwhile, according to Baron and Kenny (1986), the mediator referred to in this study includes partial mediation, because the path $\mathrm{XY}$ variable is still significant and its value decreases after the inclusion of variable $\mathrm{M}$. Argues that by meregasi identification deiri with social support reduces the impact of conditions between the two, there is an imperfect mediation model (Haslam, 2005; Haslam \& McGarty, 2003).

Agreeing with Haslam (2005), social support has a role as a mediator of social identity and stress. Branscombe (1999) complies with the argument that social identification has an effect because it basically receives and gets support from members of the group, where it can be used in coping with stress. Aspinwall and Taylor (1997) argue that information support in the social comparison process has an impact on stress. Basically gathering information to corroborate the individual's social identity will make the individual indirectly gain support from inside and outside his group, and that support will have an effect on student stress. This was confirmed by Haslam (2005) gradually, the experience of gathering support to identify himself with the informing individual. The indirect influence of social support in the process of social identity to stress has been proven by previous research, so it can be seen that the indirect effect of social support variables as a mediator of social identity and stress of students of Yogyakarta State University in the year of 2016 proved.

\section{Limitation}

In each study must have shortcomings, as well as this research. Researchers realize if these shortcomings can provide inspiration for other researchers to develop science in this field is more extensive and complex again of course. The shortcomings in this study can not be separated from the lack of researchers in the measurement. Measurements used by researchers are not too deep, so that can be used as a reference by other researchers to be used as further research.

\section{References}

Aspinwall, L.G. \& Taylor, S.E. (1997). A stitch in time: Self-regulation and proactive coping. Psychological Bulletin, 121, 417-436.

Baron, R.A. \& Byrne, D. (2004). Psikologi sosial jilid 1 (10 ${ }^{\text {th }}$ ed.). Jakarta: Erlangga.

Baron, R.M. \& Kenny, D.A. (1986). The moderator-mediator variable distinction in social psychological research: Conceptual, strategic, and statistical consi-derations. Journal of Personality and Social Psychology, 51(6), 1173-1182.

Branscombe, N.R, Schmitt, M.T., \& Harvey, R.D. (1999). Perceiving pervasive discrimination among African Americans: Implication for group identification and well-being. Journal of Personality and Social Psychology, 77, 135-149. 
Bosch, L.A., Segrin, C., \& Curran, M.A. (2012). Identity style during the transition to adulthood: The role of family communication patterns, perceived support, and affect. Identity, 12(4), 275-295.

Cassidy, T. (2004). Mapping variables related to social identity, distress and perceived health in an undergraduate student population. Social Psychology of Education, 7, 339-352.

Cheek, J.M. \& Briggs, S.R. (2013). Aspects of identity questionnaire (AIQ-IV). Measurement Instrumen Database for the Social Science, 1-4.

Cinnirella, M. (1998). Exploring temporal aspects of social identity: The concept of possible social identities. European Journal of Social Psychology, 28, 227-248.

Cohen, W.S. (1985). Health promotion in the workplace: A prescription for good health. American Psychologist, 40, 213216.

Cohen, S. (1992). Stress, social support snd disorder. In H. Veiel \& U. Baumann (Eds.), The meaning and measurement of social support. New York, NY: Hemisphere Press.

Cohen, S., Kamarck, T., \& Mermelstein, R. (1983). A global measure of perceived stress. Journal of Health and Social Behavior, 24, 385-396.

Cohen, S. \& Wills, T.A. (1985). Stress, social support, and the buffering hypothesis. Psychological Bulletin, 98, 310 -357.

Dunkley, D.M., Blankstein, K.R., Halsall, J., Williams, M., \& Winkworth, G. (2000). The relation between perfectionism and distress: Hassles, coping, and perceived social support as mediators and moderators. Journal of Counseling Psychology, 47, 437-45.

Dwyer, A.L. \& Cummings, A.L. (2001). Stress, self efficacy, social support, and coping strategies in university students. Canadian Journal of Counseling. 35(3), 208219.
D'zurilla, T.Z. \& Sheedy, C.F. (1991). Relational between social problem solving ability and subsequent level. Journal of Personality and Social Problem. American Psychological Association.

Elliott, T.R., Herrick, S.M., \& Witty, T.E. (1992). Problem-solving appraisal and the effects of social support among college students and persons with physical disabilities. Journal of Counseling Psychology, 39, 219-22

Frazier, P.A. \& Schauben, L.J. (1994). Stressful life events and psychological adjustment among female college students. Measurement and Evaluation in Counseling and Development, 27, 280-292.

Gottlieb, B.H. (1983). Social support strategies: Guidelines for mental bealth practice. California, CA: Sage Publication.

Harjana, A.M. (1994). Stres tanpa distres: Seni mengolah stres. Yogyakarta: Kanisius.

Haslam, S.A. (2005). Taking the strain: Social identity, social support, and the experience of stress. British Journal of Social Psychology, 44, 355-370.

Haslam, S.A., Jetten, J., O’Brien, A., \& Jacobs, E. (2004). Social identity, social influence, and reactions to potentially stressful tasks: Support for the self-categorization model of stress. Stress and Health, 20, 3-9.

Haslam, S.A. \& McGarty, C. (2003). Experimental design: A casuality in social psychological research. In C. Sanson, C.C. Morf, \& A.T. Panter (Eds.), Handbook of methods in social psychology (pp.235-264). Thousand Oaks, CA: Sage.

Hogg, M.A. (2004). Uncertainty and extremism: Identification with high entitativity groups under conditions of uncertainty. In V. Yzerbyt, C.M. Judd, \& O. Corneille (Eds.), The psychology of group perception: Perceived variability, entitativity, and essentialism (pp. 401-418). New York, NY: Psychology Press.

House, J.S. (1981). Work stress and social support. Reading, MA: Addison-Wesley. 
Kohn, P.M., Hay, B.D., \& Legere, J.J. (1994). Hassles, coping styles, and negative well-being. Personality and Individual Differences, 17, 169-179.

Kumar, S. \& Bhukar, J.P. (2013). Stress level and coping strategies of college students. Journal Physical Education and Sports Management, 4(1), 5-11.

Lazarus, R.S. (1984). Stress appraisal and coping. New York, NY: Springer Publishing.

Levine, R.M., Cassidy, C., Brazier, G., \& Reicher, S.D. (2002). Self-categorzation and bystander non-intervention: Two experiment studies. Journal of Applied Social Psychology, 32, 1452-1463.

Marks, D.F., Murray, M., Evans, B., \& Esticio, E.V. (2014). Health psychology: Theory, research, and practice. California, CA: Sage.

Nelson, E.S., Karr, K.M., \& Coleman, P.K. (1995). Relationships among daily hassles, optimism and reported physical symptoms. Journal of College Student Psychotherapy, 10, 11-26.

Oakes P.J., Haslam, S.A., \& Turner, J.C. (1994). Stereotyping and Social Reality. Oxford: Blackwell.

Oakland, S. \& Ostell, A. (1996). Measuring coping: A review and critique. Human Relations, 49, 133-155.

Orford, J. (1992). Community psychology: Theory and practice. New York, NY: John Wiley and Sons.

Perrez, M. (1992). Mental health and coping with everyday stressors. In M. Perrez \& M. Reicherts (Eds.) Stress, coping, and health: A situation-behavior approach (pp. 137145). Seattle, WA: Hogrefe \& Huber.

Postmes, T. \& Branscombe, N. (2002). Influence of long term racial environmental composition on subjective wellbeing in African Americans. Journal of Personality and Social Psychology, 83, 735751.
Sarafino, E.P. \& Smith, T.W. (2011). Health psychology: Biopsychological interactions. USA: John Wiley \& Son.

Stephen W., Muldoon O., Gallagher S., \& Fortune, D. (2015). Affiliative and "self as doer" identities: Relationships between social identity, social support, and emotional status amongst survivors of acquired brain injury (ABI). Neuropsychological Rehabilitation, 25(4), 555-573.

Tajfel, H. (1972) Experiments in a vacuum. In J. Israel \& H. Tajfel (Eds.), The Context of Social Psychology (pp.69-119). London: Academic Press.

Tajfel, H. (1982). Social identity and intergroup relations. Cambridge: Cambridge University Press.

Taylor, J.R. (1995). Linguistic categorization: Prototypes in linguistic theory ( $2^{\text {nd }}$ ed.). Oxford: Clarendon Press.

Towbes, L.C. \& Cohen, L.H. (1996). Chronic stress in the lives of college students: Scale development and prospective predictive prediction of distress. Journal of Youth and Adolescence.

Turner, J.C. (1982). Towards a cognitive redefinition of the social group. In $\mathrm{H}$. Tajfel (Ed.) Social identity and intergroup relations (pp. 15-40). Cambridge: Cambridge University Press.

Turner, J.C. (1991). Social influence. Milton Keynes: Open University Press.

Turner, J.C. \& Oakes, P.J. (1986). The significance of the social identity concept for social psychology with reference to individualism, interactionism and social influence. British Juornal of Social Psycho$\log y, 25,234-252$.

Wagiran. (2002). Metodologi penelitian pendidikan: Teori dan implementasi. Yogyakarta: Depublish.

World Health Organization (WHO) (2003). The health of young people: A challenge and a promise. Geneva. 